\title{
Racismo y matrices de "inclusión" de la migración haitiana en Chile: elementos conceptuales y contextuales para la discusión
}

\author{
Nicolás Rojas Pedemonte \\ Universidad Alberto Hurtado, Santiago, Chile. \\ Email:nrojas@uahurtado.cl \\ Nassila Amode \\ Universidad Alberto Hurtado, Santiago, Chile. \\ Email: nassila.amode@gmail.com \\ Jorge Vásquez Rencoret \\ Universidad Alberto Hurtado, Santiago, Chile. \\ Email: jorgeivaz@gmail.com
}

\begin{abstract}
Resumen ${ }^{1}$ : La presente reflexión se enfoca en el análisis de las representaciones y experiencias de racismo y exclusión en relación a matrices socioculturales que los migrantes haitianos identifican como posibilidades de inserción en la sociedad chilena. Contextualiza el proceso en un determinado momento histórico, social y político tanto en el país de origen como de destino; desarrollando junto con ello los conceptos de neorracismo y racismo sutil para describir experiencias, prácticas y cogniciones presentes en los discursos de los y las migrantes haitianos/as en Chile.
\end{abstract} exclusión social.

Palabras clave: migración, racismo, integración económica, Haití, Chile,

\section{Racism and "inclusion" matrices of Haitian migration in Chile: conceptual and contextual elements for discussion}

Abstract: This analysis focuses on the representations and experiences of racism and exclusion in relation to socio-cultural matrices identified by Haitian migrants as aspects that could improve the chances of integration in the Chilean society. It contextualizes the process in a particular historical, social and political moment both in the country of origin as that of destination; developing along the concepts of neo-racism and subtle racism to describe experiences, practices and cognitions present in the speeches of haitian migrants in Chile. cial exclusion.

Key words: migration, racism, economic integration, Haiti, Chile, so- 


\title{
Racismo e matrizes de "inclusão" da migração haitiana no Chile: elementos conceituais e contextuais para a discussão
}

\begin{abstract}
Resumo: Esta reflexão centra-se na análise das representações e experiências de racismo e exclusão em relação a matrizes socioculturais que os imigrantes haitianos identificam como possibilidades de integração na sociedade chilena. Contextualiza o processo num determinado momento histórico, social e político, tanto no país de origem como de destino; desenvolvendo junto com isso os conceitos de neo-racismo e racismo sutil para descrever experiências, práticas e cognições presentes nos discursos de os/asmigrantes haitianos/asno Chile.
\end{abstract}

Palavras-chave: migração, racismo, integração económica, Haiti, Chile, exclusão social.

$$
* * *
$$

\section{Introducción y reseña metodológica}

El debate sobre la migración en Chile parece haber escalado a nivel político y mediático en los últimos años, ciertamente, a luz del aumento del porcentaje de migrantes (aún bajo en relación a los países de la OCDE y frente a la media mundial), pero también por la diversificación de sus flujos. Desde el último año, el Gobierno de Chile ha encabezado un proceso de consultas para la elaboración de un nuevo proyecto de Ley Migratoria, anunciando su ingreso al Parlamento durante el primer semestre del año 2016. Mientras las organizaciones civiles y los propios migrantes esperan la instauración de un nuevo marco legal, el Departamento de Extranjería y Migraciones ha desplegado ciertas medidas administrativas provisorias que facilitan la regularidad de los visados en la población migrante. Existe relativo consenso, incluso en sectores neoconservadores (Bellolio y Errazuriz, 2014), de que la institucionalidad restrictiva de la migración, establecida durante la dictadura bajo la doctrina de la seguridad nacional (Stefoni, 2003; Jensen, 2008),no responde a los nuevos desafíos migratorios del país. Sin embargo, escasas iniciativas y discusiones se desarrollan a nivel político para contrarrestar la exclusión, la subordinación y la negación de aquellos migrantes que son signados socioestructuralmente como racial y/o culturalmente distintos y opuestos a la "identidad chilena" contemporánea, blanqueada, eurocéntrica, libremercadista y católico-conservadora (Cf. Larraín, 2001; Subercaseaux, 1997; PNUD; 2002). Desde los primeros estudios migratorios de la última década (Stefoni, 2003; Tijoux, 2007) se ha vislumbrado el racismo como un factor estructural de dominación y exclusión de los nuevos "migrantes laborales sur-sur”, y hoy frente al arribo de población afrodescendiente (principalmente desde Haití y desde el Valle del Cauca colombiano), las ciencias sociales en Chile han mostrado un renovado interés por las actuales expresiones del racismo en nuestra sociedad (Cf. Correa Tellez, 2011). En esta línea, este estudio se pregunta por la experiencia migratoria de la población haitiana en Chile, por sus representaciones sobre el racismo y por los marcos específicos de exclusión/inclusión que la sociedad chilena -desde su 
institucionalidad, mercado y cultura- le ofrecen como vías de inserción a este nuevo flujo afrodescendiente.

Mediante un estudio etnográfico desarrollado en Chile y Haití entre los meses de junio y septiembre del presente año, esta investigación ha indagado en las experiencias y significaciones de los propios haitianos involucrados en procesos migratorios hacia Chile, ya sea como sus "protagonistas" en el país de destino o -intentando evitar el "nacionalismo metodológico" en el estudio de la migración-como "referentes primarios" (familiares o amigos) de los migrantes en su lugar de origen. Se realizaron 30 entrevistas semiestructuradas a población haitiana y 8 a informantes claves. En base a los registros del Departamento de Extranjería y Migraciones de Chile y del Servicio Jesuita a Migrantes, se construyeron cuotas con cierta proporcionalidad en base a sexo, comuna de residencia y ciudad de origen. De tal modo, se entrevistó en Chile a 5 residentes en Quilicura originarios de Puerto Príncipe (3 hombres y 2 mujeres), 5 residentes en Estación Central originarios de Gonaives (3 hombres y 2 mujeres), y otros 10 residentes en comunas diversas de la Región Metropolitana como Cerrillos, San Bernardo, Pudahuel, San Miguel, Lo Espejo y Santiago (6 hombres y 4 mujeres), con diversos lugares de origen en Haití. Mientras tanto, en Haití se entrevistó a un referente (amigo o familiar) de cada entrevistado de Quilicura con origen en Puerto Príncipe y de Estación Central con origen en Gonaives. Resulta importante destacar que los entrevistados en Santiago son principalmente personas jóvenes (con un promedio de 30 años de edad; siendo el menor de 22 y el mayor de 42 años); que declaran ser mayoritariamente protestantes y en segundo lugar católicos, y que llevan relativamente poco tiempo viviendo en el país (en promedio 2 años y la persona que lleva más tiempo arribó hace 5 años, mientras que la que indica el menor tiempo de estadía registra en el país 4 meses). El perfil de la población entrevistada está asociado principalmente a migrantes de primera generación, lo que es importante considerar tanto para las reflexiones como el análisis y conclusiones del presente artículo. Se entrevistó también -como informantes claves-, al Cónsul de Chile en Haití y al director del Servicio Jesuita a Migrantes de Haití. En Chile se entrevistó a actores relevantes tales como el Cónsul de Haití en Chile, los encargados de las oficinas de migración de las Municipalidades de Estación Central y Quilicura, a dos especialistas en migración haitiana del Servicio Jesuita a Migrantes de Santiago y al Presidente de la organización de migrantes haitianos en Chile, OSCHEC. Las entrevistas fueron realizadas mayoritariamente en kreole y en algunas oportunidades en castellano o francés.

Si bien la investigación marco de la que se deriva este estudio cuenta con objetivos diversos que sobrepasan la extensión y el foco del presente texto ${ }^{2}$, la reflexión que ahora entregamos se enfoca principalmente en el análisis de las representaciones y experiencias de racismo y exclusión y en las matrices socioculturales que los migrantes haitianos identifican como posibilidades de inserción en la sociedad chilena. Para comprender estas experiencias y representaciones de la población haitiana respecto a Chile, resulta necesario contextualizar, por un lado, la migración haitiana a nivel 
mundial y particularmente en Sudamérica, como también la historia propia de Haití y el contexto de origen de quienes emprenden la travesía hacia el Sur.

\section{Antecedentes sobre el contexto de origen e impacto de factores económicos sociales y culturales en el devenir de la migración haitiana}

La historia de Haití, sin duda, es un referente entre los procesos independentistas, enfrentando como es sabido, no tan solo una lucha de independencia subversiva al orden de las metrópolis colonialistas de los siglos XVII al XIX, sino también a todos los componentes culturales, sociales, religiosos y políticos que sostenían la esclavitud como forma legítima de explotación del mercantilismo capitalista. Ya en 1804, al declarar su independencia, el pueblo haitiano da uno de los primeros gritos de lucha en el mundo en contra de todos los componentes ideológicos del antiguo orden. Se trataba de una revolución capaz de poner sobre las páginas de la historia, la voluntad de evidenciar la contradicción inminente entre los principios iluministas de justicia social que venían siendo propugnados en la época, con el sistema de reproducción de opresión, explotación, usurpación y castigo más salvajes que desarrolló el capitalismo mercantil en los últimos 400 años (Buck-Morss, 2009).

Ciertamente, hoy en día un elemento cultural característico en el país es el reconocimiento de dicha historia, el respeto a sus próceres y sus conmemoraciones patrias como el día de la independencia o la celebración del día de la bandera cada 18 de mayo en las escuelas. Así también, significativos referentes de identidad y cohesión social inicial son la lengua kreole y los aspectos culturales de la religión vudú, que trascienden la mera práctica religiosa (Gabriel sj; 2011).

A pesar de que es posible encontrar elementos, tales como los señalados, acerca de las raíces de la identidad haitiana, la conformación de dicha sociedad se encuentra cruzada desde su origen hasta el día de hoy por componentes de connotación racial, negación de libertades y condiciones de explotación. La conformación de una “nación haitiana”, cohesionada, orientada al desarrollo del bienestar de todos sus conciudadanos resulta por decirlo menos, problemática. Así bien, la conformación del Estado desde su origen, ha sido comúnmente descrita (Casimir, 2012; Grau, 2009) como sumamente compleja, ya que se combinan igualmente, a pesar de una historia "épica” compartida, tanto una lógica de conformación de clase como una lógica de pertenencia étnico-racial. Se generan (dependiendo de la contingencia histórica) alianzas y desavenencias entre una elite mulata (con pretensiones de clase dominante) con los comerciantes y hacendados blancos, pero también -en base a una solidaridad étnica (cuando estaban en juego discriminaciones raciales)-, alianzas acomodaticias con la mayoría de la población negra de los más diversos orígenes étnicos, dando curso a lo que Casimir (2012) denomina el quiebre histórico entre los primeros y los 
segundos libertos (Cf. Castor, 2012; Bourjolly, 2010). Como señala Bourjolly (2010:26. Traducción propia),en relación a esta fractura étnico-racial de clase hoy presente en distintas prácticas y lógicas reproducidas históricamente, expresiones tales como "gente de la ciudad y la gente de las afueras, analfabetos y educados, buena gente y 'vagabundos', de piel oscura y piel clara, francés y creole, vudú y cristianos, los haitianos que viven en Haití y los haitianos que viven en el extranjero, 'rocas en el agua' y 'rocas en el sol'”, resultan comunes. A partir de ello es importante destacar (más allá de las comúnmente utilizadas y conocidas estadísticas de pobreza y desarrollo humano que sitúan a Haití como uno de los países más pobres de la región), el factor étnico-racial de clase para describir la heterogeneidad y la fractura de la sociedad de origen de los migrantes haitianos en Chile. Tal perspectiva es utilizada frecuentemente para describir situaciones de discriminación, desigualdad, desventaja, vulnerabilidad y pobreza, entre una pequeña elite que concentra los recursos económicos, sociales y culturales y una mayoría pauperizada. Ello tendría implicancias en la estructuración de al menos dos históricos flujos migratorios desde Haití con sus propias particularidades: por un lado, lo que se ha denominado "la diáspora histórica" (una migración calificada, con mayor nivel de estudios, redes familiares y contactos ya sea en Estados Unidos, Francia o Canadá) y por otro, una migración "pauperizada" (con menores niveles de educación, de origen rural, en búsqueda de trabajos de subsistencia, que sufre incluso el impacto de crisis alimentarias y que históricamente migra a República Dominicana a trabajar en los ingenios de azúcar). Ciertamente, estos flujos no han sido estáticos, pues responden no sólo a las condiciones de origen, sino también a la apertura o cierre de fronteras por parte de los estados receptores o en otros términos, lo que Saskia Sassen ha conceptualizado como guestoraliens en relación a dichos flujos migratorios en el actual contexto del sistema mundo (Sassen, 2000).

Sumado a lo anterior, por lo general se consideran otros tres momentos históricos importantes durante el siglo XX, tanto en la conformación de la sociedad haitiana como también en el desarrollo de sus procesos migratorios. El primer momento corresponde a la intervención e invasión de Estados Unidos en 1915 hasta 1934, cuya impronta impuesta se orientaba a la modernización de la producción, no así, necesariamente, el desarrollo de principios constitutivos de un estado de derecho democrático. Concretamente, se traducía en la utilización de la mano de obra haitiana en la producción de caucho y en el control del tránsito del canal de Panamá, junto al desarrollo de una normativa y una regulación migratoria entre Haití y República Dominicana, que promovía el desarrollo de haciendas azucareras en territorio dominicano con mano de obra haitiana. Tal antecedente sociohistórico, permite considerar en perspectiva el hecho que dicha migración se remonte a principios del siglo XX y que no implica un fenómeno reciente.

Un segundo momento hace referencia a los gobiernos autoritarios de la dinastía de François Duvalier, iniciada en 1956 (durante los años de la Guerra Fría) y restaurada en 1971 con el ascenso al poder de su hijo JeanClaude hasta su derrocamiento en 1986. Estos son años se han denominado 
comúnmente como de "terror" y de dictadura debido a la existencia de los tristemente célebres “Tonton Macoute” y "Leopardos”, cuyas acciones tuvieron como efecto directo el destierro y el exilio de un amplio grupo de haitianos que dejan el país por razones de persecución política, hacia Latinoamérica (países cercanos), Canadá, Estados Unidos y otros países. Dicho contexto, permite comprender también en perspectiva los orígenes de lo que anteriormente se ha descrito como "la diáspora histórica” haitiana y esas primeras generaciones que comienzan a conformar comunidades en dichos países de destino. No obstante, también hay antecedentes propios de las últimas décadas que son altamente determinantes de los procesos migratorios contemporáneos.

El auge y declive de la acción colectiva conducida por el movimiento “Lavalas”, la sucesión de gobiernos de Jean Bertrand Aristide y Preval interrumpidos entre 1991 y 1994 por el golpe de estado del general Cedras y luego, el derrocamiento de Aristide en 2004 con la subsiguiente intervención y ocupación de una misión militar de Naciones Unidas, que se extiende hasta el día de hoy (2015), son hitos recientes que han ido -valga la paradoja- consolidando una profunda inestabilidad política. Este escenario ha propiciado el rótulo peyorativo de Estado fallido, Estado débil o Estado frágil para describir una ingobernabilidad estructural del Estado haitiano y el descrédito y la desconfianza en sus instituciones y agencias. Si se suma a ello el descalabro de la crisis humanitaria producido por los efectos del terremoto de enero del año 2010 (Brutus y Chalmers, 2010) -y el brote de cólera derivado-, se puede observar un tercer momento de expulsión masiva de personas, algunas de ellas en condición de refugiados, y otras en búsqueda de mejores oportunidades de vida en el extranjero, aprovechando ya sea sus capacidades personales y/o las redes presentes en el extranjero.

En la actualidad, se considera como un factor expulsor de población migrante la dificultad que tiene el país para instaurar un régimen democrático y una democracia participativa, traduciéndose -como lo menciona Atria et al. (2013) para el caso chileno-, en una crisis de representatividad ${ }^{4}$. Sin desconocer los históricos factores de expulsión ya presentados, Haití vive una coyuntura socio-política que hace pensar que la migración a terceros países sigue siendo una alternativa de mediano y corto plazo, sustentada en un "imaginario de estabilidad y democracia” en relación a sus principales “referentes migratorios”: Canadá, Estados Unidos, Francia o Países del Caribe y más recientemente, Sudamérica. Como ejemplo de este punto se pueden observar ciertos hitos tales como: a) El atraso por más de dos años en la elección de dos tercios del parlamento que lleva en diciembre del 2014 a la renuncia del primer ministro Laurent Lamothe, y a la necesidad crítica de conformar un Consejo Electoral Provisional que asegure elecciones durante el año 2015,mientras por su parte, un número importante de protestas y manifestaciones exigían la renuncia del presidente Martelly, quien a partir del 12 de enero del 2015, producto de la disolución del parlamento, comienza a gobernar por decreto; b) la realización finalmente de elecciones parlamentarias que se realizan durante agosto del 2015 con una baja participa- 
ción ciudadana y elecciones presidenciales en octubre del mismo año con 54 candidatos a la presidencia; c) los paros de transportistas que paralizan Puerto Príncipe durante los meses de febrero y marzo producto del aumento del precio de los combustibles; d) el recrudecimiento de los casos de cólera durante el primer trimestre del año y una disminución de los fondos para su control por parte de la comunidad internacional producto de la emergencia del Ébola en el África sub-sahariana; y sumado a todo lo anterior, e) un deterioro en las relaciones con República Dominicana, producto de la entrada al consulado dominicano de manifestantes haitianos a fines de febrero frente a la puesta en marcha por parte del gobierno dominicano (junio) del decreto ley que no reconoce la nacionalidad de dominicanos con ascendencia haitiana ${ }^{5}$. Este complejo escenario durante el tercer trimestre del presente año se caracteriza además por los cierres de frontera, más los paros de transportistas dominicanos que alegaban inseguridad en Haití, junto a las represalias del comercio de productos dominicanos por parte del gobierno, que tensionaron durante el resto del año las relaciones bilaterales. Con todo, MINUSTAH ${ }^{6}$, luego de más de diez años de intervención y presencia en el país, decide postergar su retirada definitiva hasta el 2016.

Resultan manifiestas aquellas adversidades contextuales que enfrentan quienes emigran del país y quienes permanecen en él y que ayudan a comprender en una lógica transnacional e históricamente situada, la decisión de migrar. En la mayor parte de los casos, hoy los procesos de movilidad territorial no corresponden -en estricto rigor-, a una expulsión por persecución política, o por catástrofe humanitaria o natural, pero, sí es el resultado de múltiples factores que se combinan históricamente en la decisión de migrar como en la percepción de la situación del país de origen y de llegada (como también en la evaluación de la experiencia migratoria en Chile, tanto en términos de proyecto de vida personal como colectivo). Concretamente, dimensiones de la experiencia migratoria como la exclusión, el racismo y la discriminación, no son sino vivenciadas e interpretadas por los propios migrantes bajo el prisma de su propia historia y contexto de origen.

\section{La migración haitiana hacia Chile y Sudamérica}

La migración haitiana hacia Chile y Sudamérica es un fenómeno que hoy no cumple más de una década, pero que tiene larga data hacia países como República Dominicana, Estados Unidos, Canadá y Europa (principalmente, Francia). En efecto, la diáspora haitiana en el mundo, se estima en 2 millones de habitantes (Nieto, 2014). Los nuevos factores de expulsión en la última década que ya nombramos, han dado pie a un nuevo patrón migratorio con disposición a asumir mayores riesgos y costos en sus travesías hacia nuevos rumbos, en una lógica de "sálvese quien pueda" (Metzner, 2014: 43), identificando a países sudamericanos como Brasil y Chile como lugares de destino. Los migrantes haitianos han identificado en Brasil y Chile nuevos destinos con promesas de bienestar económico, estabilidad, seguridad y posibilidades reales de ingreso regular. Como indica Villanueva,“Esta promesa de futuro ha ido poco a poco insertándose en 
campos nuevos, en circuitos de expectativas para miles de migrantes que antes miraban a Estados Unidos, Canadá, Francia o España como destinos posibles.” (Villanueva, s/f: 23). Las estimaciones de la población haitiana en Brasil ascienden a 50.000 personas (Metzner, 2014) y en Chile, según estimaciones oficiales (Departamento de Extranjería y Migraciones), a 6.0007. Frente a la tendencia general a la feminización de la migración Sur-Sur en Sudamérica, éste se trataría de un flujo masculinizado, con 80\% de hombres en Brasil (Metzer, 2014) y 75\% en Chile (DEM, 2014), con un incipiente aumento de las mujeres por reunificación familiar.

En términos generales, se trata de una migración con experiencias previas de movilidad territorial en sus trayectorias laborales y vitales (Valenzuela et. al, 2014: 107) y además con la proyección de extender sus horizontes hacia el hemisferio norte. Tanto la bibliografía existente sobre el flujo hacia Brasil (Metzner, 2014: 15), como nuestras propias indagaciones en Chile, indican que estos países sudamericanos serían destinos eventualmente transitorios en sus proyectos migratorios. Hoy estos flujos serían caracterizados principalmente por hombres jóvenes, que extienden su tiempo de estadía en el país de destino -aumentando la posibilidad de radicación- cuando consiguen dominar el idioma, insertarse en empleos estables y establecer finalmente proyectos familiares.

A diferencia de otros flujos migratorios sur-sur, el haitiano ingresa a Chile directamente por el Aeropuerto Internacional de Santiago, lo que se traduce en un bajo porcentaje de ingreso clandestino y de irregularidad en su condición migratoria ${ }^{8}$. Por su parte, contrario a los supuestos sobre las razones forzosas de su migración, presentan prácticamente un nulo porcentaje de visados por refugio (aun cuando es cierto que la tendencia actual de los gobierno de la región es a restringir estos visados), frente al 42,9\% que accede a visa sujeta a contrato y 54,5\% a visa temporaria (registros del DEM para el período 2010-2013). Tales condiciones legales, supondrían mejores condiciones que el resto de la población migrante latinoamericana en Chile, sin embargo ese supuesto resulta cuestionable en aspectos como la segregación socio espacial y la precariedad laboral que experimentan, reproduciendo las desventajas mayoritarias de la población migrante intrarregional en el país. Su alta concentración en comunas de bajos ingresos y de carácter periférico (según los registros del DEM, en Quilicura reside un 38,9\%, en Estación Central 15,7\%, en Santiago Centro 7,9\%, en Independencia 4,9\% y en San Bernardo 3,2\%), da cuenta de la segregación, el escaso acceso a servicios públicos de calidad y la alta exposición a la inseguridad ciudadana que experimentan cotidianamente. Su inserción en el mercado del trabajo está marcada por la segmentación y la precariedad laboral y tal como lo describe Valenzuela et al. (2015)y lo corroboran entrevistas del presente estudio, tienden a realizar trabajos asalariados con jornadas más extensas que lo permitido, trabajos no calificados (desaprovechamiento de calificaciones), como ocurre en el caso de los hombres, empleos en centros de lavados de autos, bombas de bencina, pequeños talleres y bodegas, y en el caso de las mujeres, en labores de ventas y limpieza. Generalmente, por más precarios que sean los empleos, no les cuesta mu- 
cho tiempo encontrarlos, pues son favorecidos por la condición regular de la mayoría de sus visas y la valoración positiva que han generado entre los empleadores chilenos, quienes los consideran más responsables y disciplinados entre los migrantes sur-sur (Cf. Solimano et al. 2012: 43). Son precisamente estas condiciones las que, en la precariedad generalizada del trabajo migrante en Chile, les propician aparentemente, condiciones menos desventajosas que la mayor parte los migrantes latinoamericanos ${ }^{9}$.

Con todo, ciertos indicios destacados en la literatura revisada-y los hallazgos de este estudio-, destacan entre la población haitiana una evaluación negativa de la cultura chilena y del trato recibido: "(existe) un discurso de disconformidad en términos muy personales y enfáticos que aluden a la poca solidaridad, la falta de educación y a lo individualista de la sociedad chilena” (Villanueva (s/f: 19). Sin duda la migración haitiana en Chile estaría enfrentando significativas barreras para su inclusión plena, en base al reconocimiento de sus particularidades y potencialidades, entre ellas: la barrera lingüística (genera dificultades en cada momento de la inserción, como en los aspectos burocráticos-legales, laborales y educacionales), racial-cultural (prejuicios raciales y de clase asociados a la imagen de un país profundamente "subdesarrollado"), institucional (una ley que no favorece la regularidad migratoria), educacional (trabas en la convalidación de títulos que les exige volver a cursar estudios escolares incluso a quienes cuentan con estudios universitarios) y climática (vulnerabilidad a enfermedades respiratorias frente a las bajas temperaturas).

La siguiente sección expone los principales elementos conceptuales que orientarán el análisis de la información recaba en el presente estudio.

\section{Aproximación al concepto de racismo y sus variantes actuales en relación a la migración haitiana en Chile}

El racismo no es un concepto fácil de definir dado su carácter ideológico y polémico, y por cierto, también producto de las mutaciones históricas a las que ha estado sujeto a nivel práctico y discursivo. El presente apartado busca aproximarse a una definición general del concepto, insistiendo en sus expresiones más actuales en la sociedad moderna, así como también entregar un referente analítico para el análisis de la población en estudio. En sentido restringido, entendido como "las teorías raciales", el racismo refiere a la creencia en la existencia de diferencias biológicas hereditarias entre los grupos humanos, las cuales derivan en valoración de diferencias morales y de capacidades. Se concibe generalmente, como un principio de clasificación identitario, o diferenciación entre los grupos sociales, y jerarquización, en cuanto existirían razas superiores a otras (Benedict y Weltfish, 1943). En este sentido, constituye una base para el rechazo y la discriminación, y llega a justificar desde el mero desprecio, pasando por la explotación, hasta el exterminio de aquellas razas consideradas inferiores. 
En cuanto ideología, el racismo no es una simple actitud propia de los sujetos racistas (el racismo va más allá de sus mecanismos psicológicos), por lo que Balibar (Balibar y Wallertstein, 1991: 32) lo define como:

“[un] verdadero "fenómeno social total”, [que] se inscribe en prácticas (formas de violencia, de desprecio, de intolerancia, de humillación, de explotación), discursos y representaciones que son otros tantos desarrollos intelectuales del fantasma de profilaxis o de segregación (necesidad de purificar el cuerpo social, de preservar la identidad del "yo", del "nosotros", ante cualquier perspectiva de promiscuidad, de mestizaje, de invasión), y que se articulan en torno a estigmas de la alteridad (apellido, color de la piel, prácticas religiosas)”.

En la actualidad la objetividad científica del concepto de raza ha sido extensamente cuestionada y las teorías raciales, con sus aplicaciones dramáticas (desde la colonización hasta los distintos genocidios), igualmente condenadas. Sin embargo, esto no ha significado la desaparición de las lógicas racistas (entendidas como lógicas de segregación y exclusión social), ni de las propias prácticas racistas. Al contrario, el racismo se habría adaptado a la conciencia antirracista moderna al sustituir las categorías raciales por el determinismo cultural. Así, se habría consolidado un nuevo racismo, "racismo diferencialista” (Taguieff, 1988) o "neorracismo" (Balibar, 1991). Se trata de

"un racismo cuyo tema dominante no es la herencia biológica, sino la irreductibilidad de las diferencias culturales; un racismo que, a primera vista, no postula la superioridad de determinados grupos o pueblos respecto a otros, sino "simplemente" la nocividad de la desaparición de las fronteras, la incompatibilidad de las formas de vida y de las tradiciones.” (Balibar, in Balibar y Wallerstein, 1991:37)

Así, el discurso neorracista se estructuraría en torno a "estigmas de la alteridad" ya no estrictamente codificados en términos raciales, reemplazándolos por otros conceptos, tales como "etnia” o incluso "inmigración”. Pero a pesar de estos cambios en su lenguaje, el neorracismo no deja de cumplir las funciones tradicionales del racismo: al naturalizar (ya no desde la biología sino desde la cultura) las diferencias entre los grupos sociales, abandona sólo superficialmente su lógica de jerarquización, para finalmente seguir justificando formas de exclusión, desprecio y opresión de los grupos considerados minoritarios en sociedades que formalmente se consideran igualitarias. Savater (1993: 24), lo explica con claridad:

"Ambos fatalismos sociales (racismo biologista y determinismo culturalista) coinciden (...) en su visión anticonvencionalista y falsamente natural del orden comunitario, pero también en otro punto importante: su fobia al mestizaje. Los racistas y los hiperculturalistas proclaman siempre como ideal de la colectividad bien nacida el mantenimiento de la prístina pureza o su recuperación caso de que -como suele pasar- se haya perdido" 
Por lo demás, en el contexto neoliberal actual se ha planteado que el racismo llega a ser paradójicamente funcional al capitalismo, por lo que se debería considerar una "norma” más que una "patología” de la modernidad (Traverso, 2011 : s/p). A pesar de que el determinismo racial o cultural contradice la ideología universalista a la base del sistema económico actual (ya que pretende explicar la desigualdad socioeconómica por diferencias en términos de mérito y de capacidades individuales), el racismo -al igual que el sexismo- continúa siendo un factor predominante de la división axial del trabajo, en cuanto permite asignar los puestos menos valorados y remunerados a grupos "étnicos” específicos (Wallerstein, in Balibar y Wallerstein, 1991). Por su parte, la flexibilidad del racismo actual constituiría una verdadera oportunidad para la economía capitalista. Como bien lo explica Wallerstein (Balibar y Wallerstein, 1991: 56-57)
"Este tipo de sistema -un racismo constante en la forma y en el veneno, aunque un tanto flexible en sus fronteras- hace sumamente bien tres cosas. En primer lugar, permite ampliar o contraer, según las necesidades del momento, el número de individuos disponibles para los cometidos económicos peor pagados y menos gratificantes en un ámbito espacio-temporal concreto. Por otra parte, hace nacer y recrea permanentemente comunidades sociales que en realidad so- cializan a sus hijos para que puedan desempeñar, a su vez, las fun- ciones que les corresponden (aunque, desde luego, les inculcan también formas de resistencia). Por último, ofrece una base no meritocrática para justificar la desigualdad”

Así bien, en un clima intelectual marcado por cierta desacreditación del concepto de raza y por una cultura internacional de derechos humanos (Correa Tellez, 2011: 23), el racismo sigue existiendo, sin embargo, se expresa menos explícitamente, tanto a nivel institucional, con políticas nacionalistas que procuran "no reconocer" en vez de excluir abiertamente, como de interacciones sociales a nivel micro (racismo cotidiano), donde el rechazo, inaceptable de ser reconocido socialmente, se transfigura y camufla en "prejuicio sutil” (Meertens y Pettigrew, 1997).

Conforme a esto, se reflexiona sobre las características de racismo, neo-racismo o prejuicio sutil hacia los migrantes latinoamericanos y caribeños en el contexto chileno, donde la nación y la clase tienden a aparecer como matrices privilegiadas de un racismo que no siempre se expresa de manera sutil.

En Chile, como en la mayoría de las sociedades receptoras de migrantes, el racismo está fuertemente condicionado por la ideología nacionalista y por mecanismos y representaciones de la jerarquización de clases. Existiría una fuerte imbricación entre raza, clase y nación (Cf. Balibar y Wallerstein, 1991), donde, por una parte, la raza constituye un componente importante dentro de la ideología nacional. Como plantea Cárdenas (2006: 102), en Chile "la construcción mítica de la idea de nación ha ido siempre acompañada de afirmaciones taxativas sobre la homogeneidad racial, cultu- 
ral y religiosa de nuestra población.” La idea de nación siempre se basa en la ficción o construcción ideológica de una comunidad homogénea (Cf. Anderson, 1983), la cual se define en gran parte en términos étnicos o raciales. En Chile, la construcción histórica del imaginario nacional, a pesar de sus tensiones y giros estratégicos (Cf. Aravena y Silva, 2009), estaría fuertemente marcada por la idea de raza chilena en cuanto identidad étnica basada en lo “criollo”, en línea con la oposición sarmientina de “civilización” versus “barbarie”. Esta construcción identitaria de la nación chilena combina en concreto la negación del otro (principalmente, indígena) y la valoración de la ascendencia europea (Cf. Larraín, 2001; Subercaseaux, 1997). Además, este relato nacional estaría vinculado a cierto darwinismo social (Subercaseaux, 2007) en la medida en que la construcción de la alteridad étnica sirve de justificación para la desigualdad socioeconómica. En este sentido, la ideología nacional provee

“códigos de reproducción y jerarquías naturalizadas que legitiman el lugar central del hombre blanco y proclaman, con una fuerza y eficacia que han desafiado los siglos, el lugar subordinado del otro -indio, mestizo o mulato_ c cuya inferioridad se constata en la vida cotidiana a partir de pautas estéticas y morales convertidas en naturaleza y sólidamente implantadas en la cultura” (Margulis\&Urresti, 1999:48).

En este marco, nacionalismo, racismo y clasismo se retroalimentan y refuerzan mutuamente. Resulta entonces que el racismo hacia los migrantes latinoamericanos y caribeños en Chile encuentra sus mejores argumentos dentro de la ideología nacional, según la cual ellos no cabrían dentro de los límites de la supuesta identidad étnica de la nación chilena (cuyo linaje europeo supuestamente sería predominante), hecho que justificaría su inferiorización a nivel moral y socioeconómico. Este racismo, en cuanto ideología estatal-nacional, no solo se desplegaría a nivel de representaciones sociales, sino que se difundiría también a través de las instituciones y políticas (incluyendo los vacios institucionales y políticos) del Estado.

En contexto de inmigración económica, como lo sugerimos anteriormente, el racismo hacia los migrantes latinoamericanos y caribeños resulta particularmente funcional en la medida en que autoriza la explotación laboral de las minorías en el marco de una división axial étnica del trabajo, mientras se van potenciando imaginarios sociales que asocian ciertos nichos laborales a nacionalidades específicas: “la nana peruana”, “el lavador de autos haitiano”, etc. Se trata finalmente de una etnicización o racialización de la mano de obra. en cuanto se les asigna características específicas a los trabajadores migrantes según su lugar de origen, y no sobre sus capacidades o credenciales educacionales, para colocarlos en los puestos de trabajo más precarios. En este fenómeno, el Estado neoliberal chileno, con su tendencia a la desregulación, tendría una responsabilidad importante. Tal como lo indican Tijoux y Díaz Letelier (2014: 303)

“El racismo de Estado, en un contexto de alta migración trabajadora y porosidad de las fronteras, opera biopolíticamente dejando vivir y 
dejando morir. Por una parte, “deja vivir” a individuos y grupos en la condición de discriminados que sirven como mano de obra del trabajo precario -gestionando de paso el ilegalismo, al dejar proliferar la mano de obra barata del condenado a la figura de inmigrante-ilegal. Por otra parte, el racismo de Estado "deja morir" a los inmigrantes durante o tras la expropiación de sus fuerzas de trabajo en condiciones abiertamente desreguladas -con toda la precariedad, inseguridad y exposición a maltratos impunes que ello implica-, abandonándolos, desprotegiéndolos y finalmente desechando sus cuerpos ya inservibles."

Finalmente, existirían en Chile -unas veces explícitas y otras solapadas- ciertas prácticas, discursos e instituciones fuertemente marcadas por un racismo cuyas matrices privilegiadas serian la ideología nacional y el clasismo, justificando el desprecio, la explotación o el rechazo de ciertos grupos migrantes. Pero ya que este racismo nunca se asume como tal, cabe preguntarse cómo es percibido y experimentado por los propios migrantes y cómo se traduce en sus posibilidades concretas de inclusión/exclusión. ¿Acaso lo identifican con facilidad y lo cuestionan o, frente a las limitadas opciones de inserción en la sociedad chilena, pueden llegar a adherir a esta ideología de manera adaptativa obviando sus consecuencias? Éstas corresponden a interrogantes importantes de considerar, tomando en cuenta -como ya se ha señalado- cómo la historia y el contexto de origen inciden en la evaluación que hacen del racismo los propios migrantes haitianos, en lo que atañe a su relación con la sociedad chilena y también con sus propios compatriotas.

\section{Representaciones del racismo y matrices de inserción en el discurso de los migrantes haitianos en Chile}

En las entrevistas, realizadas el concepto de racismo es evitado generalmente por los haitianos, sin embargo se identifican relatos explícitos sobre prácticas racistas por parte de la sociedad chilena. Algunas de estas prácticas pueden ser insultos explícitos, como lo relata un joven originario de Gonaives que trabaja en una gasolinera: "un día un cliente me dijo 'negro sucio' mientras cargaba bencina. Me dijo 'perro negro'” (hombre, 26 años, Estación Central, Gonaives). Otras veces lo reconocen en un trato diferencial en la prestación de servicios, como lo indica uno de los entrevistados con mejores condiciones laborales y con mayor tiempo de estadía (6 años): "muchas veces cuando uno va a un espacio, tienden a atender a un chileno antes que a un extranjero, más aún si uno es de color de piel distinto" (hombre, 33 años, Pudahuel, Puerto Príncipe). Otros entrevistados han descrito abusos laborales, que si bien no los conceptualizan explícitamente como racismo, sí como los identifican como discriminación:

"en el último trabajo tuve una dificultad en el sueldo, no me querían pagar. Eso fue también por la comunicación, porque todavía no ha- 
blo bien español, es difícil por eso poco tiempo después lo deje. Después me di cuenta que eso fue por la discriminación, razón por la cual lo dejé, ellos me hicieron trabajar mucho más que los chilenos casi todo lo hago yo hice mucho más de lo que tengo que hacer en mi espacio de trabajo. No les hacían hacerlo a los chilenos pero me hacían hacerlo a mí, entonces fue que dije "es porque soy haitiano que me lo hacen hacer", es un abuso eso" (hombre, 33 años, Quilicura, Puerto Príncipe).

Con todo, el racismo frente a los migrantes y en particular contra los migrantes haitianos la mayor parte de las veces no es del todo explícito. En línea con el desarrollo de un neorracismo, la discriminación cultural-racial identificada por los entrevistados, se expresa la mayor parte del tiempo como un racismo sutil. En el trabajo -principal o único ámbito donde se relacionan con la sociedad chilena- las relaciones parecen estar marcadas por un trato diferenciado en favor de los chilenos. Incluso cuando consideran que las relaciones no son malas, identifican desventajas: "En el trabajo siempre lo mismo, los chilenos pueden hablar un montón, disfrutar, y el jefe no les molesta, a mí sí. (...) no me tratan mal pero siento que me tratan diferente, ya sea el jefe o los colegas” (hombre, 29 años, San Bernardo, Cabaret). Y este sutil trato desventajoso por ser "haitianos", los entrevistados lo asocian concretamente a dimensiones raciales de la mano de aspectos clasistas. "Normalmente por la diferencia de la piel no tenemos una muy buena relación, ellos no lo demuestran pero es así, solamente nos saludamos” (mujer, 31 años, Quilicura, Puerto Príncipe), sostiene una entrevistada para graficar la barrera que "la piel”, genera en su relación con los chilenos.

Sin embargo, esta barrera también se asocia -según indican- a cierta inferioridad material e intelectual que los chilenos le atribuirían a los haitianos, como pobres y tontos, basados en los supuestos de la crisis humanitaria de Haití y en la distancia idiomática que algunos manifiestan respecto al castellano. Esta es una visión compartida entre los entrevistados, es decir que: "ser migrante haitiano en Chile, es ser pobre, según el chileno, por falta de información” (hombre, 33 años, Pudahuel, Puerto Príncipe). Estas preconcepciones de los chilenos sobre los haitianos, representarían para los éstos barreras concretas que impiden una fluida convivencia, limitándola a una mera coexistencia (Cf. Giménez, 2005). El relato de un joven haitiano, es ilustrativo:

"No me siento cómodo porque uno de los problemas que tengo con los chilenos es cuando alguien no puede hablar o no tiene un nivel avanzado de español, ellos piensan qué ignorante o tonto, que ha salido de una familia pobre, miserable aunque pase dos años y medio en el trabajo, sinceramente no me siento cómodo y aunque hablo y río con los chilenos, realmente no hay feeling”. (hombre, 27 años, Quilicura, Puerto Príncipe)

Sin embargo, los entrevistados suelen naturalizar el racismo y la discriminación percibida, indicando que "todos los países son racistas" 
(hombre, 27 años, Estación Central, Gonaives), incluso Haití. Y la comparación frente a los tratos recibidos en República Dominica, parece ser favorable para Chile, y ciertamente, suaviza toda crítica al racismo percibido en el país. La culpa no la tendrían los chilenos pues "no están acostumbrados a ver negros" (hombre, 36 años, Quilicura, Saint-Marck) y si los haitianos son abusados y discriminados, simplemente es "porque no saben defenderse" (hombre, 25 años, San Miguel, Mirabalais) o “dan la ocasión” para que los discriminen (hombre, 34 años, Quilicura, Cabo Haitiano). En general, la discriminación estaría asociada a la debilidad de las víctimas, pues concretamente los entrevistados dicen tener "la autoestima" (Ibídem) y "la capacidad para sobre llevar esa diferencia” (hombre, 33 años, Quilicura, Puerto Príncipe). Sin duda, frente a las adversidades materiales y la convulsionada vida política descrita en las secciones anteriores, en la cultura haitiana la fortaleza es valorada como una condición básica para la supervivencia.

Con todo, resulta particularmente preocupante como los entrevistados desarrollan una evaluación acrítica del racismo y la discriminación, incluso culpando a sus propios compatriotas, en lo que puede reconocerse como un fenómeno de "incorporación del estigma" (Goffman, 2006). Si bien son capaces de reconocer estos procesos, no los “dramatizan", argumentando que son parte de las "reglas del juego", y destacan optimistamente que aquello no será óbice para la consecución de los objetivos de sus proyectos migratorios: principalmente la inclusión económica en la sociedad chilena. Concretamente, manifiestan que tienen plena claridad sobre sus objetivos y que la discriminación o el racismo no los distraerá de sus proyectos de desarrollo personal y económico. Los entrevistados -a modo de autoafirmación étnica, tienden recurrentemente en sus discursos a destacar sus ventajas como fuerza de trabajo (imagen que los empleadores comienzan a asumir y fomentar), tanto frente a los chilenos como frente a otros colectivos migrantes ${ }^{10}$.

Mientras critican desde una marcada "ética protestante"11, la falta de disciplina y rectitud de los chilenos, enfatizan que están mejor preparados que ellos para las exigencias del mercado laboral: el rigor de la educación haitiana los haría más capaces e inteligentes, pero además su compromiso religioso los hace más confiables, disciplinados y respetuosos que el resto. Esta autopercepción y la lectura que hacen de la cultura y del mercado laboral chileno, les permite autorrepresentarse como ejemplares idóneos para el éxito económico en la sociedad chilena. Las adversidades y la ausencia de soportes institucionales en Chile pasan a un segundo plano frente al proyecto que reconstruyen en función del escenario que enfrentan: constituirse principalmente en "sujetos de crédito”. La inclusión política, la ciudadanía, y la condición de sujetos de derecho, parecen cuestiones de algún modo secundarias frente a una matriz socioeconómica neoliberal conservadora chilena que aparentemente valora lo que ellos mejor saben hacer: trabajar responsablemente y seguir instrucciones, por más exigentes que sean. Los entrevis- 
tados evidencian proyectos migratorios marcados por la individuación (Cf. Charry y Rojas Pedemonte, 2013) y la autorrealización personal (aunque combinados con una fuerte solidaridad mecánica con sus familiares en origen y con una significativa participación en espacios comunitarioreligiosos), donde anhelan desarrollarse educacional y laboralmente para luego regresar a aportar lo aprendido a Haití. Esto lo manifiesta la mayoría de los entrevistados, especialmente los más jóvenes, sin embargo con el paso del tiempo en Chile, la “inclusión” neoliberal vía mercado, parece inclinar estos sueños a la concreción de proyectos marcadamente económicos, especialmente entre quienes se quedan y desarrollan proyectos familiares en el país:

“Bueno, sí existe la discriminación acá, además en todos los países existe la discriminación. A veces me ven en el mercado [Feria de Lo Valledor] y me preguntan si soy haitiano y me dicen algo para que me sienta mal, pero no me molesta porque todo lo que puede un chileno lo puedo también. Puedo comprar con crédito como un chileno” (hombre, 42 años, Lo Espejo, Gonaives).

Sin duda, la inclusión como "sujetos de crédito”, y no como "sujetos de derecho”, responde a una adecuación estratégica de los proyectos migratorios de los haitianos, exacerbando aquellas cualidades que aparentemente la cultura y el mercado chileno, mientras atenúan otras. Por ejemplo, algunos reconocen ser "ruidosos" en sus celebraciones, pero eso no deja de posicionarlos como los más proclives a una adaptación virtuosa y respetuosa al modelo chileno. Características como esta podrían ser fuentes de conflicto en la convivencia en los vecindarios y podrían cuestionar la imagen disciplinada que proyectan, sin embargo, le restan centralidad en sus relatos y, simplemente, las comentan al margen. Se estaría posiblemente frente a una reconstrucción identitaria que, por ejemplo, atenúa las características festivas podrían disonar con la identidad chilena construida en oposición a los “tropicalismos” (Cf. Larraín, 2001). Sin duda, la inserción económica a través de un mercado laboral chileno, flexible y segmentado, no garantiza la inclusión de esta población y la torna altamente vulnerable a posibles crisis económicas. Esto representa uno de los aspectos más preocupantes, como también que este tipo de inserción y las cualidades exaltadas en los haitianos se constituyan en una exigencia para el resto de los migrantes. Por cierto, también es riesgoso que esta complacencia con la acogida brinda, y la negación del racismo que manifiestan los haitianos, contribuya -aunque modestamente- a perpetuar el neorracismo en Chile y valide, en última instancia, un modelo carente de derechos y marcado por la precariedad laboral, las arbitrariedades y las asimetrías entre capital y trabajo. 


\section{Diagrama 1. Matrices de inserción y representaciones de la migración haitiana en Chile}

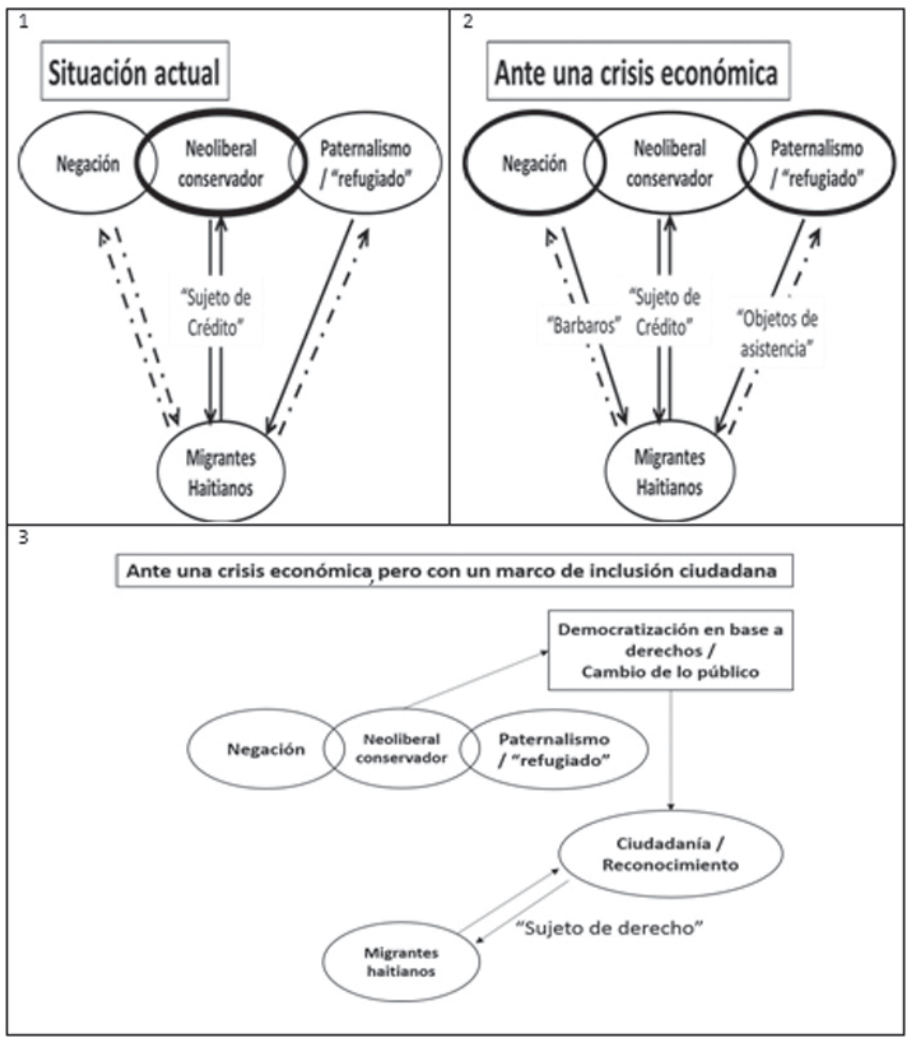

Fuente: elaboración propia

Este diagrama busca ilustrar las vías de inserción de los migrantes haitianos en Chile en función de distintas matrices socioeconómicas, que corresponden en concreto a marcos cognitivos e institucionales. A partir de estas matrices se construyen y difunden determinadas representaciones de los migrantes haitianos ("sujeto de crédito", "objeto de asistencia”, bárbaros” o "sujetos de derecho”). Los migrantes pueden sintonizar o no con estas matrices a través de estas representaciones, incorporando, exacerbando o atenuando determinadas pautas y características socialmente construidas. En el caso de la migración haitiana, como se expresa en cuadrante 1 del Diagrama 1, se identifica actualmente una significativa sintonía con la matriz neoliberal conservadora chilena, lo que concretamente se expresa en una inserción económica encarnada en la figurada -idealiza o prometida- de un "sujeto de crédito" que 
podría gozar de los beneficios del consumo. Este "sujeto de crédito", más que a la figura de un emprendedor conquistador del mercado, se asociaría principalmente a la figura de un ejemplar padre de familia proveedor. Ciertamente, la "ética haitiana" descrita por los entrevistados, su disciplina, su abnegación, su religiosidad (principalmente, protestante), su valoración del trabajo y la familia, parecen alcanzar significativa sintonía con la matriz neoliberal conservadora del Chile contemporáneo. Sin duda, la reconstrucción de la identidad de los haitianos en Chile resuena con la identidad chilena conservadora y neoliberal (Cf. Subercaseaux 2007; Larraín, 2001), y particularmente con el arquetipo del padre de familia trabajador y disciplinado, incluso sumiso y despolitizado: arquetipo chileno representado, por ejemplo, por "Juan Herrera” ícono de la galardonada serie televisiva Los 80.

Siguiendo las reflexiones de Eduardo Thayer (2014), esta vía de inserción es frágil. Ante una eventual crisis económica, estos "sujetos de crédito" (efectivos o aspirantes) podrían ser -como muestra el cuadrante 2- directamente excluidos. Los haitianos precariamente incluidos vía mercado, podrían, desde la matriz izquierda, ser negados como "bárbaros" (incluso con políticas antimigrantes como las desarrolladas en la Europa de la reciente crisis) o en el "mejor" de los casos, desde la matriz paternalista, ser inferiorizados como "objetos de asistencia”, representados como "pobres”, "incapaces" o, sin necesariamente serlo, tratados como "refugiados". Es precisamente la matriz de la ciudadanía y el reconocimiento, la que garantiza la inclusión de los migrantes como sujetos de derechos y los resguarda frente a los embates de una posible crisis y de sus arbitrariedades derivadas. Por cierto, esta última matriz en el Chile neoliberal solo existe como proyecto, y son más bien los impulsos democratizadores desde la propia Sociedad Civil la que ha abierto la discusión sobre lo público y sobre la instauración de un modelo en base a derechos (Cf. Atriaet al., 2013). Con todo, los discursos recabados entre los entrevistados no manifiestan una especial sintonía con este proceso politizador y democratizador. Fruto de experiencias carentes de derechos en Haití como también de las promesas y limitaciones que el modelo neoliberal chileno les presenta, los migrantes haitianos parecen hoy, como "sujetos de crédito" (principalmente aspirantes), lejanos cognitivamente -y también políticamente- de la matriz de la ciudadanía, distantes de ésta como proyecto ${ }^{12}$. 


\section{Diagrama 2. Migrantes haitianos en Chile frente al racismo. Autorrepresentación y representación del “otro” connacional.}

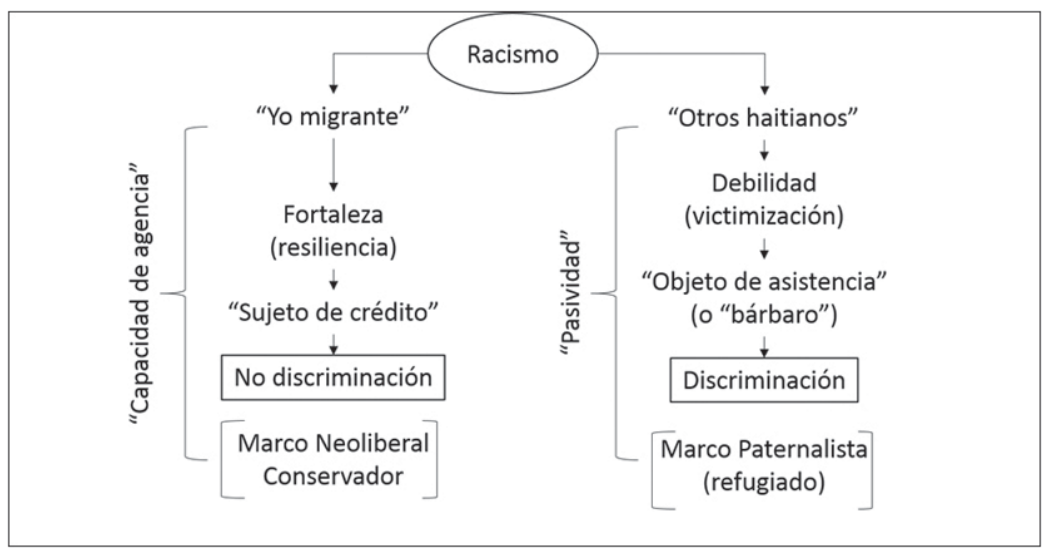

Fuente: Elaboración propia en base a entrevistas realizadas.

Hay dos aspectos que destacan en los proyectos migratorios de los haitianos entrevistados, la autorrealización personal (individuación) y la solidaridad mecánica con sus familias, la que se actualiza cotidianamente, ya sea compartiendo con familiares en Chile o mediante el contacto transnacional con quienes se quedaron en el lugar de origen. Estas dos dimensiones conectan con la matriz neoliberal conservadora, respectivamente, con la imagen del "actor económico" y con la del "padre de familia recto y ejemplar”. No obstante, en la exacerbación de la dimensión económica de sus proyectos de realización personal y en la aceptación de las reglas del juego de la sociedad de mercado chilena, se profundizan las línea divisorias entre la autopercepción del "yo migrante haitiano" y la representación del "otro migrante haitiano". Precisamente esta contraposición de representaciones es expresada en el Diagrama 2. Este diagrama grafica cómo frente al racismo -que asumen como natural y universal- los haitianos construyen la autoimagen de un migrante haitiano que sabe enfrentar el racismo sin devenir en un actor discriminado, frente a los "otros migrantes haitianos" que identifican como débiles y responsables de su propia discriminación. Respecto la discriminación racial frases como la siguiente alcanzan cierta recurrencia en las entrevistas: "a mí no me ha pasado, pero puede ser que otros haitianos sí permitan que los discriminen" (hombre, 34 años, Quilicura, Cabo Haitiano).

Como se indicó más arriba, para los entrevistados no sería la sociedad chilena -que reconocen tan racista como todas-, la responsable de los abusos y la discriminación, sino el propio haitiano que no se adapta a las reglas el juego y que finalmente permite que lo atropellen. Mientras el clivaje 
de mayor probabilidad en una sociedad poco inclusiva para los migrantes opondría a un "nosotros los haitianos" y "ellos los nacionales”, la tendencia identificada en las entrevistas contrapone un "yo migrante haitiano aspirante a sujeto de crédito” (fuerte, hábil, proactivo, civilizado y buen trabajador) que no se deja discriminar, frente a un "los otros migrantes haitianos objetos de asistencia” (débiles, pasivos, poco inteligentes y bárbaros) que permiten los abusos.

Se reconoce en los entrevistados una tendencia a idealizar y admirar un concepto simbólico de patria haitiana, pero serían proclives a expresar cierto menosprecio por el resto de los haitianos que estaría llegando a Chile y que sufren el racismo. Directamente los describen como carentes de la fortaleza necesaria, de las habilidades y la inteligencia necesarias para la supervivencia y para la adaptación a los escenarios adversos de la migración. En muchas ocasiones, más que un cuestionamiento a los "racistas", la preocupación de los entrevistados está más puesta en la manera en que demuestran que, a pesar de "ser racialmente distintos", son tanto o más capacitados que los chilenos: es decir, más que criticar el racismo lo legitiman, intentando contrarrestarlo con las virtudes que para los chilenos serían valoradas. Frente a la pregunta de si son discriminados los haitianos en Chile, un entrevistado es particularmente elocuente sobre la representación negativa del "otro bárbaro haitiano responsable por su propia discriminación”:

"Sí, porque hay haitianos que generan eso. Incluso yo siento ganas de discriminarlos cuando los veo. Es su comportamiento que genera eso. Si uno es extranjero y viene a Chile tiene que comportarse como chileno, no puede adoptar una actitud distinta. Si todo el mundo entra a las 8, uno también tiene que entrar a las 8. Pero a ellos les resulta imposible, porque tú vas en la calle y puedes ver un grupo de tres haitianos hablando creole muy alto. A mí no me gusta eso, me molesta, porque los blancos no saben lo que ellos están diciendo. Puede molestar a los demás. Y de ahí viene la discriminación. Hasta yo lo siento así”. (Hombre, 26 años, Estación Central, Gonaives).

Si bien existen organizaciones haitianas en Santiago, como OSCHEC, con importantes iniciativas autoafirmativas de su cultura de sus derechos como trabajadores y migrantes, sin lugar a dudas, esta vía de inserción económica y la trasmutación de los proyectos de individuación en simple individualismo y desprecio del connacional, erosiona la solidaridad mecánica entre ellos. Es posible suponer que con esta inserción meramente económica -con sus prácticas y representaciones derivadas-, se minan las posibilidades de conformar una comunidad migratoria haitiana que brinde reales oportunidades de inclusión social a sus miembros (Cf. Amode y Rojas Pedemonte, 2015). 


\section{Conclusiones}

El análisis de las representaciones de los migrantes haitianos en torno al racismo y la discriminación racial que experimentan en Chile, permitió observar ciertas disposiciones de gran relevancia para comprender las nuevas facetas del racismo y su siempre estrecha relación con el fenómeno migratorio. En especial, resulta significativo que, a pesar de reconocer y describir situaciones en las cuales sufrieron prácticas o discursos manifiestamente racistas, se nieguen, hasta cierto punto, a denunciar el racismo como tal. Esto, de cierta manera, contradice la clásica idea según la cual las víctimas del racismo necesariamente serían antirracistas y corrobora las aproximaciones teóricas contemporáneas sobre el neorracismo. Aunque la muestra de este estudio no se construyó en base al activismo político de cada entrevistado, se han identificado varios rasgos discursivos sobre el racismo que tienen más que ver con la aceptación, tolerancia y resignación, que con la crítica y lucha contra la ideología, los prejuicios y los actos racistas. Así, características comunes dentro del discurso de los migrantes haitianos son la naturalización del racismo, su atenuación frente a las metas económicas individuales e incluso la responsabilización de sus connacionales sobre este fenómeno, por no ser capaces de "jugar el juego" de la migración, dentro del cual el racismo seria una regla más. Todo esto se traduce en una actitud que consiste principalmente en esquivar, ignorar o justificar el racismo y sus efectos, en pos de la concreción sus objetivos migratorios: principalmente la inserción económica en la sociedad chilena. La disposición a asumir los elevados costos de esta inserción (el racismo, el desarraigo, las precariedades laborales, etc.) mientras sea posible alcanzar el status de sujeto de crédito, como consumidores y "buenos trabajadores”, da cuenta de una acentuada capacidad adaptativa y por sobre todo de una gran resiliencia en la población haitiana que llega a Chile.

Para explicar esta resiliencia es posible formular dos hipótesis: primero, ésta tendría que ver con el contexto de origen de estos migrantes; luego, se vería reforzada en destino en pos de sus proyectos migratorios y sus expectativas de inserción económica. En efecto, para entender la evaluación que los migrantes haitianos hacen del racismo en Chile, resulta necesario preguntarse primero si efectivamente lo conceptualizan según los mismos estándares que la sociedad chilena. En este sentido, se podría sostener que la evaluación del racismo es función de las representaciones de la alteridad racial -históricamente construidas- en origen, así como de las experiencias de racismo vividas antes de llegar a Chile. Provenir de un contexto donde el racismo y sus efectos están fuertemente presentes y si, además, se ha experimentado en "carne propia”, aumenta posiblemente el umbral de tolerancia (o de resignación) por arriba de los umbrales de las personas que nunca lo han vivenciado. En esta perspectiva, resulta interesante indagar en la conformación del imaginario nacional haitiano, cruzado, como se ha visto, por conflictos y tensiones raciales, para comprender los significados concretos que tiene para un haitiano la palabra "racismo" y conocer su propia aprehensión del fenómeno racista. La segunda explicación de esta suerte de "estoicismo" en los migrantes haitianos, sería la 
priorización de sus proyectos migratorios, principalmente de sus objetivos económicos. De alguna forma, el racismo es ocultado porque no es funcional al cumplimiento de las metas migratorias, las cuales aparecen exclusivamente asociadas a la inserción económica, posiblemente porque el mercado aparece como la única vía de inserción que la sociedad chilena les ofrece.

De alguna forma, el imaginario neoliberal conservador vigente en Chile y con el cual sintonizarían buena parte de los migrantes haitianos, condiciona sus reacciones frente al racismo, al valorar y difundir como normas sociales y morales la competencia, el consumo, el individualismo y el éxito personal (Lamont et al, 2013). Estos valores o registros impuestos por el neoliberalismo conservador, precisamente no ayudan a generar una consciencia ni una denuncia del racismo como tal. Aunque identifiquen abusos, los entrevistados no identifican los mecanismos de una dominación que se justifica en base a criterios raciales/culturales. Resulta entonces que no se facilitan las condiciones para formular estrategias colectivas de resistencia o lucha contra el fenómeno, el cual incluso se suele abordar, por parte de los haitianos entrevistados, desde una perspectiva individual. Sin duda, los resultados de este estudio exploratorio no son definitivos y en futuras investigaciones, resultaría oportuno indagar si acaso estas estrategias pragmáticas tienen un correlato en cierta cultura de la "resistencia de los dominados”, en lenguaje de James Scott (2003). Identificar, sin más, pasividad o irreflexividad en estos actores, ciertamente, puede ocultar resistencias menos explicitas que el clásico activismo de pancartas y consignas altisonantes.

Por cierto, el hecho de que los migrantes no perciban el racismo o no lo denuncien, no implica que no sean víctimas de prácticas y discursos racistas. La sociedad chilena no puede entonces festejar su escaso racismo y su carácter acogedor en base al discurso complaciente de estos colectivos migrantes. Lo que ocurre en este discurso es justamente una invisibilización del racismo y la exclusión detrás del imaginario neoliberal. Estos discursos acríticos recabados también tienen como escenario, la escasez de oportunidades y de vías de inserción, donde la única vía que se les propone es la inserción económica. Por cierto, se trata de una inserción que, además es muchas veces sinónimo de malas remuneraciones, descalificación y explotación laboral. Al no poder proyectarse más allá de la esfera económica, los migrantes haitianos, muchas veces, prefieren considerar su experiencia en Chile como provisoria y abandonan sus expectativas de una verdadera inclusión.

Por último, es importante destacar que el perfil asumido y proyectado por los migrantes haitianos, si bien representa importantes aportes para la sociedad chilena, existe el riesgo de que se constituya en el parámetro exigido para el resto de los migrantes e incluso para la misma clase trabajadora chilena. La positiva disposición de la población haitiana a asumir las reglas del juego neoliberal, supone el peligro de constituirse en la "mano de obra” dócil y dispuesta a las arbitrariedades de un modelo caracterizado por las asimetrías entre capital y trabajo. El modelo neoliberal chileno podría 
encarnar -y seguramente ya lo está haciendo- en colectivos así de vulnerables y bien dispuestos (valga la redundancia)la“carne de cañón” ideal, que asumiría los costos y las supuestas "externalidades" de la producción neoliberal. Esa es una de las principales preocupaciones que plantea esta investigación, como también la posibilidad de que sean estos aspirantes a “sujetos de crédito” el primer fusible de una eventual crisis económica. 


\section{Notas}

${ }^{1}$ Documento realizado en base a la investigación en curso "Migración haitiana hacia Santiago de Chile: origen y aterrizaje de nuevos proyectos migratorios", desarrollada por el Área de Estudios Sociales SJ del Centro Fernando Vives (Universidad Alberto Hurtado) y el Servicio Jesuita a Migrantes de Chile. Junio-diciembre 2015.

${ }^{2}$ Los objetivos de aquella investigación son los siguientes: 1.- Describir los proyectos -motivaciones, expectativas, recursos e información- de la población haitiana que migra a Santiago; 2.- Identificar las rutas de la migración haitiana hacia Santiago y sus riegos; 3.- Describir las experiencias de inserción-con sus factores exclusores e inclusores- de la población migrante haitiana en la sociedad chilena; 4.- Caracterizar a nivel sociodemográfico y laboral a la población haitiana en Santiago; 5.- Conocer y describir los contextos sociales y familiares de origen; 6.- Identificar prácticas y discursos de alcance transnacional en la migración haitiana a Santiago; 7.- Proponer medidas políticas inclusivas tanto en origen como en destino.

${ }^{3}$ Denominaciones de las respectivas policías secretas conocidas como aparatos represivos de los regímenes correspondientes.

4 "Lo que caracteriza a estas crisis no es la acción ilegal de uno o varios manifestantes, sino la incapacidad del sistema político de procesar las demandas populares y, correlativamente, la indiferencia del pueblo ante las instituciones políticas” (Atria et al., 2013:87).

5 Sentencia 0168-13, emitida por el Tribunal Constitucional de la República Dominicana, que aplica de manera retroactiva criterios que excluyen del iussolis, vigente hasta la promulgación de la Constitución de 2010 a los nacidos desde 1929 en territorio dominicano, cuyos padres estuvieran al momento de su nacimiento, en situación migratoria irregular. Ciertamente, esta medida que ha sido profundamente criticada por la comunidad internacional por su contradicción con los derechos internacionales. Sus repercusiones, aún por verse, trascienden las posibilidades de extensión del presente artículo, aunque, claramente, tiene un impacto innegable en la coyuntura del migrante haitiano durante el último año y en la proyección de los procesos migratorios desde Haití hacia el Sur.

${ }^{6}$ Misión de estabilización de las Naciones Unidas en Haití.

${ }^{7}$ Esta cifra, sin duda, subestima el total de la población haitiana en Chile, pues, según reportes de la Policía de Investigaciones de Chile (PDI), solo entre el 1 de enero y el 19 de noviembre de 2015 ingresaron 8869 turistas de aquella nacionalidad (54\% más que en el 2014), frente a sólo 449 que salieron del país con aquel visado. Estas cifras no hablan necesariamente de una mayor facilidad en el ingreso durante el último año, pues frente a los 612 haitianos reembarcados ("rechazados" enviados de regreso) en 2014 por la PDI desde el Aeropuerto Internacional de Santiago, hasta el 19 de noviembre los reembarcados haitianos durante el 2015 ascendían a 1273.

${ }^{8}$ Los registros del Servicio Jesuita a Migrantes de Santiago indican que menos del 1\% de los haitianos que acudieron a esta organización entre 2010 y mayo de 2015 recurrió a esta alternativa, frente al 3,3\% del total de la población migrante que reconoce ingreso por pasos no autorizados. 
${ }^{9}$ Calculando el índice de inclusión laboral construido por Bueno y Rojas Pedemonte (2014) con datos de Solimano et al. (2013) para la Región Metropolitana de Santiago, los haitianos se posicionan en el segundo lugar del ranking de inclusión laboral, sólo superados por los argentinos. Los peor situados en el ranking son los originarios de Bolivia y República Dominicana; estos últimos ciertamente condicionados por el visado que se les exige para ingresar como turistas y por las condiciones de vulnerabilidad y riesgo que enfrentan en sus migración a Chile cuando no cuentan con las condiciones exigidas.

10 "Me gusta Chile porque la mayoría de los chilenos saben que los haitianos son buenas personas que están aquí para trabajar y estudiar, y eso es todo. Es diferente para los colombianos. Yo trabajo con colombianos. Y el trato que recibí por parte de los chilenos, ellos nunca lo han recibido” (hombre, 26 años, Estación Central, Gonaives).

11 Se reconocen, a simple vista, ciertas analogías a la ética protestante weberiana asociada al calvinismo, sin embargo, el protestantismo haitiano guarda particularidades importantes de estudiar con mayor profundidad.

${ }^{12}$ Aun cuando existen a nivel mundial experiencias donde las personas se logran constituir en "sujetos de derecho" y "de crédito" a la vez, los migrantes haitianos se insertan en el modelo neoliberal de la sociedad de consumo chilena, donde se restringe la "ciudadanía” mientras se exacerba un marcado consumismo individualista. 


\section{Bibliografía}

Amode, N. y Rojas Pedemonte, N. (2015), "Las paradojas de las redes migratorias”. En Guizardi, Menara. Las fronteras del trasnacionalismo, Ocho Libros, Santiago.

Anderson, B. (1983), Imagined communities: reflections on the origin and spread of nationalism, Pacific Affairs, London.

Aravena, A. y Silva, F. (2009), “Imaginarios sociales dominantes de la alteridad en la configuración de los límites etno-nacionales de la identidad chilena”, en Sociedad Hoy, núm. 17, Concepción.

Atria, F.; Larraín, G.; Benavente, JM; Couso, J; Joignant, A. (2013), El otro modelo, del orden neoliberal al régimen de lo público. Debate. Santiago.

Balibar, E. y Wallerstein, I. (1991), Raza, nación y clase, Madrid.

Bellolio, A. y Errazuriz, H. (2014), Migraciones en chile: oportunidad ignorada, Libertad y Desarrollo, Santiago.

Benedict, R. y Weltfish, G. (1943), The Races o Mankind, En Public Affairs Pamphlet No. 85, Columbia.

Bourjolly, J.-M. (2010), “Haïti: quellereconstruction?” en Buteau, Pierre; Saint-Éloi, Rodney; Trouillot Lyonel (eds.) Refonder Haiti? Mémoire d'encrier. pp. 25-32.,Port-au-Prince.

Buck-Morss, S. (2009), Hegel, Haiti, and Universal History. University of Pittsburgh Press. Pittsburgh.

Brutus, É. y Chalmers C. (2010), 'Construire ou reconstruire Haïti ? Acteurs, enjeux et représentations’ en Buteau, Pierre; Saint-Éloi, Rodney; Trouillot Lyonel (eds.) RefonderHaiti?Mémoired'encrier. pp. 33-45. Port-au-Prince.

Cárdenas, M. (2006), “«Y verás cómo quieren en chile...»: Un estudio sobre el prejuicio hacia los inmigrantes bolivianos por parte de los jóvenes chilenos”, en Ultima década, 14(24), en línea.

Casimir, J.(2012), “Haití y sus élites: el interminable diálogo de sordos” en Casimir, Jean. Haití de mis amores. Ambos Editores. pp. 157-224.

Castor, S. (2012), “Les racines séculaires d'une difficile construction nationale” en Rainhorn, Jean-Daniel (ed.) Haïti réinventer l'avenir Editions de la maison des sciences de l'homme, Editions de l’Université d'État d'Haïti. pp. 35-43. Port-au-Prince. 
Charry, C. y Rojas Pedemonte, N. (Eds.) (2013), La Era de los Individuos. Actores, política y teoría en la sociedad actual. Santiago de Chile: LOM. Correa Tellez, J. (2011), Ser “inmigrante” en Chile: la experiencia del racism cotidiano de peruanos y peruanas en la ciudad de Santiago. Tesis para optar al título de socióloga. Santiago de Chile.

Gabriel, A. sj. (2011), La Cérémonie du Bois-Caïman et le sens du vodou dans les lutes identitaire, religieuse et politique du people haïtien. Centre de Recherche, de Réflexion, de Formation et d'Action Sociale (CERFAS). Portau-Prince.

Gaune, R. y Lara, M. (eds.) (2009), Historias de Racismo y Discriminación en Chile". Santiago de Chile.

Giménez, C. (2005), “Convivencia: Conceptualización y sugerencias para la praxis”. En Cuadernos Puntos de Vista, Observatorio de las Migraciones y de la Convivencia Intercultural de la Ciudad de Madrid, Madrid.

Goffman E. (2006), Estigma. La identidad deteriorada. Amorrortu, Buenos Aires.

Grau, M. I. (2009), La revolución negra, la rebelión de los esclavos en Haití 1791-1804, Ocean Sur. Santiago.

Lamont, M., Welburn, J. S. y Fleming, C. S. (2013), "Responses to Discrimination and Social Resilience Under Neoliberalism: The United States Compared”. Pp. 129-157. En Hall, P.A y Lamont, M. (eds.) Social Resilience in the Neoliberal Age, Social Resilience in the Neoliberal Age, Cambridge University Press, Cambridge

Larraín, J. (2001),Identidad Chilena, LOM ediciones,Santiago.

Margulis, M. y Urresti, M. (1999), La segregación negada. Cultura y discriminación social, Editorial Biblios, Buenos Aires.

Meertens, R. y Pettigrew, T. (1997), “Is subtle prejudice really prejudice?” in Public Opinion Quarterly, Oxford.

Metzner, T. (2014), La migración haitiana hacia Brasil: estudio en el país de origen. En La migración haitiana hacia Brasil: características, oportunidades y desafíos (Cuadernos migratorios $n^{\circ} 6$ ). Buenos Aire,s OIM.

Nieto, C. (2014), Migración haitiana a Brasil: Redes migratorias y espacio social transnacional. CLACSO, Buenos Aires

PNUD (2002), Informe de Desarrollo Humano en Chile, "Nosotros los chilenos: un desafío cultural. PNUD, Santiago de Chile. 
Polis, Revista Latinoamericana, Volumen 14, $N^{\circ}$ 42, 2015

Sassen, S. (2000), Guest and Aliens. The new press.New York.

Savater, F. (1993), “La heterofobia como enfermedad moral”, Vuelta, 17, N. 205, México

Scott, J. (2003), Los dominados y el arte de la resistencia. Ediciones Era; México.

\section{SJM 2015}

Solimano, A., Mellado, V., Araya, C., Lahoz, S., y Ocon, Y. (2012),Incorporación laboral de los migrantes en la Región Metropolitana de Chile, OIM, Santiago

Stefoni, C. (2003), Inmigración peruana en Chile. Una oportunidad a la integración. Editorial Universitaria, Santiago.

Subercaseaux , B (1997),Historia de las ideas y de la cultura en Chile. Tomo IV: Nacionalismo y cultura, Editorial Universitaria, Santiago.

Idem (2007), “Raza y nación: el caso de Chile”, en A Contra corriente, una revista de historia social y literatura de América latina, vol.5, $n^{\circ} 1$, en línea.

Taguieff, P. A. (1988), La Force du préjugé, La Découverte, Paris.

Thayer, L.E.(2014), “Condiciones y desafíos para la construcción de una política de reconocimiento y la inclusión de los migrantes en Chile.”, En Rojas Pedemonte, N. y Vicuña Undurraga SJ, J (eds.)Migración y Trabajo, OIM/Ciudadano Global, Santiago.

Tijoux, M. E. (2007), “Peruanas inmigrantes en Santiago. Un arte cotidiano de la lucha por la vida”, en Polis [En línea], 18 | 2007, en línea.

Tijoux, M. E. y Diaz Letelier, G. (2014), “Inmigrantes, los “nuevos bárbaros” en la gramática biopolítica de los estados contemporáneos”, en Quadranti - RivistaInternazionale di Fi losofiaContemporanea Volume II, $n^{\circ} 1$, 2014, online.

Traverso, E. (2011), “La fabrique de la haine : Xénophobie et racisme en Europe. », en Contretemps, en línea.

Valenzuela P., Riveros, K., Palomo, N., Araya, O., Campos, B. Salazar, C. y Tavie, C. (2014), "Integración laboral de los inmigrantes haitianos, dominicanos y colombianos en Santiago de Chile.” En Revista Antropologías del Sur $\mathrm{N}^{\circ} 2 \cdot 2014$ Págs. 101-121, Santiago. 
Villanueva, A. (s/f), Construcción del relato biográfico y proyecciones de vida. Versiones de la migración haitiana en Santiago de Chile.Clacso, Buenos Aires.

Recibido: 15.11.2015

Aceptado: 20.12.2015 